\title{
EFEITOS E AFETOS DA RACIONALIDADE SOCIAL CONTEMPORÂNEA
}

\author{
Marco Naccarato*
}

RESUMO: Na tentativa de descrever efeitos e afetos que surgem no interior da racionalidade social contemporânea, o artigo parte do discurso de formatura proferido pelo escritor David Foster Wallace no Kenyon College, em 2005, para estabelecer relações entre as descrições do novo capitalismo de Richard Sennett, e a nova racionalidade social do neoliberalismo de Pierre Dardot e Christian Laval, que apontam diversas formas pelas quais o modo de vida dos indivíduos na sociedade é condicionado. Utilizando-se do diagnóstico desses autores, propomos uma aproximação entre os efeitos produzidos por essa racionalidade social e a dinâmica de afetos presente no sistema filosófico de Espinosa.

Palavras-chave: afetos, capitalismo, neoliberalismo.

ABSTRACT: In an attempt to describe effects and affections that arise inside the contemporary social rationality, the article starts with the graduation speech given by writer David Foster Wallace at Kenyon College in 2005, to establish relations between the description of the new capitalism of Richard Sennett, and the new social rationality of neoliberalism from Pierre Dardot and Christian Laval, which point out several ways in which the way of life of individuals in society is conditioned. Using the diagnosis of these authors, we propose an approximation between the effects produced by this social rationality and the dynamics of affections present in the Spinoza's philosophical system.

Keywords: affections, capitalism, neoliberalismo.

Em maio de 2005, o escritor norte-americano David Foster Wallace proferiu o discurso de abertura da cerimônia de graduação dos formandos do Kenyon College, em Ohio, nos Estados Unidos. No início de sua fala, apresenta uma metáfora, como segue:

[...] Dois jovens peixes estão nadando juntos e cruzam com um peixe mais velho nadando em sentido contrário, que os cumprimenta e diz "Bom dia, garotos. Como está a água?". E os dois jovens peixes nadam mais um pouco, e então um deles olha

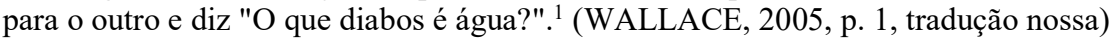

O discurso descreve males e agruras da vida adulta na sociedade norte-americana contemporânea, a qual fatalmente os estudantes estarão submersos em breve. Aparte de seu

\footnotetext{
* Graduando em Filosofia pelo UNIFAI - Centro Universitário Assunção.

${ }^{1}$ There are these two young fish swimming along and they happen to meet an older fish swimming the other way, who nods at them and says "Morning, boys. How's the water?" And the two young fish swim on for a bit, and then eventually one of them looks over at the other and goes "What the hell is water?".
} 
caráter ideal e certo tom de nostalgia juvenil (uma vez que considera o jovem estudante ainda não inserido nessa vida adulta), sua fala propõe, como saída para uma sociedade entediada, frustrada e depressiva, que o propósito real da formação educacional seria o de fomentar nos indivíduos um estado apurado de consciência e empatia, que forneceria elementos para perceber melhor o outro e o mundo ao redor e escapar do comportamento social padrão (default setting), a saber, um tipo de egoísmo dogmático ou certeza cega que os impede de se conscientizarem sobre o que seria a água.

E eu sugiro que este é o real valor, sem besteiras, do que sua educação em artes liberais deveria ser: como evitar viver sua confortável, próspera, respeitável vida adulta morto, inconsciente, um escravo de sua mente e de sua configuração padrão natural de ser unicamente, completamente, imperialmente sozinho, dia após dia. Isso pode soar hiperbólico, ou absurdamente abstrato. Vamos deixar mais concreto. O fato é que vocês graduandos não fazem ideia do que "dia após dia" realmente significa. Há por acaso grandes partes da vida adulta americana que ninguém fala em discursos de formatura. Uma dessas partes envolve tédio, rotina, frustrações triviais. Os pais e os mais velhos aqui saberão muito bem do que estou falando. ${ }^{2}$ (WALLACE, 2005, p. 45, tradução nossa)

O que Wallace descreve em seu discurso é uma enxurrada de efeitos e sintomas produzida por uma subjetivação constituída no quotidiano dessa sociedade. Embora o escritor não tenha se ocupado em diagnosticar o que provocaria esses sintomas, sua vida adulta encontra formal correspondência com a descrição de novo capitalismo apontada por Richard Sennett, e com aquilo que Pierre Dardot e Christian Laval denominam de nova razão, a racionalidade do neoliberalismo, que dá forma para um tipo de indivíduo surgido na contemporaneidade, o sujeito empresarial, condicionado pela eficiência competitiva, por uma concepção de empresade-si-mesmo e pelo hiperindividualismo.

Para Sennett, o capitalismo atual, diferentemente de sua versão anterior moldada na linha de montagem, é mais dinâmico e enfatiza o risco, o curto prazo e a flexibilização do trabalho. Aparentemente mais "humano", pois permitiria uma liberdade maior aos indivíduos, acaba por produzir desorientação e ansiedade, que afetam a construção de identidade dos sujeitos e suas relações em sociedade.

A flexibilidade hoje traz de volta esse sentido arcano de job, na medida em que as pessoas fazem blocos, partes de trabalho, no curso de uma vida.

\footnotetext{
2 And I submit that this is what the real, no bullshit value of your liberal arts education is supposed to be about: how to keep from going through your comfortable, prosperous, respectable adult life dead, unconscious, a slave to your head and to your natural default setting of being uniquely, completely, imperially alone day in and day out. That may sound like hyperbole, or abstract nonsense. Let's get concrete. The plain fact is that you graduating seniors do not yet have any clue what "day in day out" really means. There happen to be whole large parts of adult American life that nobody talks about in commencement speeches. One such part involves boredom, routine, an petty frustation. The parents and older folks here will know all too well what I'm talking about.
} 
É bastante natural que a flexibilidade cause ansiedade: as pessoas não sabem que riscos serão compensados, que caminhos seguir. (SENNETT, 2015, p. 9)

Como se podem buscar objetivos de longo prazo numa sociedade de curto prazo? Como se podem manter relações sociais duráveis? Como pode um ser humano desenvolver uma narrativa de identidade e história de vida numa sociedade composta de episódios e fragmentos? [...] Se eu fosse explicar mais amplamente [...], diria que o capitalismo de curto prazo corrói o caráter [...], sobretudo aquelas qualidades de caráter que ligam os seres humanos uns aos outros, e dão a cada um deles um senso de identidade sustentável. (SENNETT, 2015, p. 27)

Essa nova forma de trabalho favorece continuamente o desaparecimento de virtudes como confiabilidade, comprometimento e ajuda mútua, provocando o principal problema apontado por Sennett: a corrosão do caráter. O caráter pessoal, definido por ele como "aspecto a longo prazo de nossa experiência emocional. [...] expresso pela lealdade e o compromisso mútuo, pela busca de metas a longo prazo, ou pela prática de adiar a satisfação em troca de um fim futuro. (SENNETT, 2015, p.10)", é produzido pelo desenvolvimento de uma narrativa de vida, que é impelida pelo novo capitalismo.

Em consonância com as considerações de Sennett, Dardot e Laval descrevem extensamente o neossujeito dessa nova racionalidade social, que entende a si mesmo como empresa, capital e produto. Enquanto capital humano, carece de uma constante autovalorização ordenada pela lógica do modelo de empresa, e no intuito de desempenhar melhor sua vida profissional e pessoal, já que não estão dissociadas, apela para "asceses do desempenho", um conjunto de técnicas que visa fortalecer ou adaptar melhor o indivíduo à realidade e se valorizar tal qual um capital. Sendo produto, se vê inserido na norma da concorrência, como item na prateleira.

Se a ética neoliberal do eu não se restringe aos limites da empresa, é não só porque o ser bem-sucedido na carreira confunde-se com o ser bem-sucedido na vida, mas, ainda mais fundamentalmente, porque a gestão moderna tenta "aliciar as subjetividades" com a ajuda de controles e avaliações de personalidade, inclinações de caráter, maneiras de ser, falar e mover-se, quando não de motivações inconscientes. (DARDOT; LAVAL, 2016, p. 338)

O que é suficiente estabelecer aqui é que a ascese da empresa de si mesmo termina com a identificação do sujeito com a empresa, deve produzir o que chamamos antes de sujeito do envolvimento total [...]

[...] lidamos aqui com o que Éric Pezet denominou judiciosamente "asceses do desempenho", as quais constituem um mercado em plena expansão.

Diferentes técnicas, como coaching, programação neurolinguística (PNL), análise transacional (AT) e múltiplos procedimentos ligados a uma "escola" ou um "guru" visam a um melhor "domínio de si mesmo", das emoções, do estresse, das relações com clientes ou colaboradores, chefes ou subordinados. (DARDOT; LAVAL, 2016, p. 339) 
Em especial, o que Dardot e Laval deflagram é que nessa nova racionalidade social o sofrimento emocional dos indivíduos se justifica por um cálculo de acumulo de capital, uma vez que este sofrimento carece ser administrado pelo próprio sujeito para que ele consiga ser o mais produtivo possível. Desse modo, o neossujeito arremessado à concorrência e ensimesmado na construção e valorização de si, experimenta uma autorrepressão, a depressão como padrão e a desconfiança como ordenadora das relações.

\begin{abstract}
Vimos antes que a neogestão tende a controlar comportamentos e atitudes, solicitando um esforço constante de autocoerção. Essa "ascese" a serviço do desempenho da empresa, [...] normatiza as condutas, ao mesmo tempo que demole os engajamentos dos sujeitos uns com os outros. (DARDOT; LAVAL, 2016, p. 365)

Mais amplamente, a ideologia do sucesso do indivíduo "que não deve nada a ninguém", a ideologia do self-help, destrói o vínculo social, na medida em que este repousa sobre deveres de reciprocidade para com o outro. Como manter juntos sujeitos que não devem nada a ninguém? Provavelmente a desconfiança, ou mesmo o rancor, em relação aos mais pobres, aos preguiçosos, aos velhos dependentes e aos imigrantes, tem um efeito de "cola" social. Mas ela também tem seu reverso, se todos se sentem ameaçados de um dia se tornarem ineficazes e inúteis. (DARDOT; LAVAL, 2016, p. 366)
\end{abstract}

Se a gestão do sofrimento do sujeito empresarial, percebida no esforço de autocoerção de que falam Dardot e Laval, deflagra que o sofrimento é força produtiva, ela também mostra o quanto o funcionamento emocional dos indivíduos é abalado e o quanto sua experiência afetiva se torna empobrecida.

O represamento do indivíduo sob essa racionalidade social tem efeitos em sua subjetividade, na construção de uma narrativa pessoal e na formação de seu caráter, bem como na relação com a alteridade. Tudo deságua no conjunto de sintomas retratado pelo discurso de Wallace: frustração, tédio, depressão, individualismo, isolamento, ansiedade etc. Este mar de afetos que inunda a vida do homem da atualidade é produto da vida adulta ou default setting, do novo capitalismo, da nova racionalidade social do neoliberalismo, ou, para consubstanciar tais denominações numa metáfora, produto da água.

Nesse sentido, a aproximação que propomos entre o pensamento de Espinosa e o modo de vida contemporâneo parte da adaptação dos indivíduos ao modelo de empresa e da autoimposta gestão das emoções, que não são somente fracas alternativas em como lidar com esses afetos, mas produtos dessa adaptação, uma vez que colocam os sujeitos sob permanente sujeição à norma dessa racionalidade, da forma mais pobre possível, conforme apresentado até aqui. Apta em descrever esse processo, a dinâmica dos afetos espinosana é definida da seguinte forma: 
1. Chamo de causa adequada aquela cujo efeito pode ser percebido clara e distintamente por ela mesma. Chamo de causa inadequada ou parcial, por outro lado, aquela cujo efeito não pode ser compreendido por ela só.

2. Digo que agimos quando, em nós ou fora de nós, sucede algo de que somos a causa adequada, isto é (pela def. prec.), quando de nossa natureza se segue, em nós ou fora de nós, algo que pode ser compreendido clara e distintamente por ela só. Digo, ao contrário, que padecemos quando, em nós, sucede algo, ou quando de nossa natureza se segue algo de que não somos causa senão parcial.

3. Por afeto compreendo as afecções do corpo, pelas quais sua potência de agir é aumentada ou diminuída, estimulada ou refreada, e, ao mesmo tempo, as ideias dessas afecções.

Explicação. Assim, quando podemos ser a causa adequada de alguma dessas afecções, por afeto compreendo, então, uma ação; em caso contrário, uma paixão. (SPINOZA, 2013. Ética, III Parte, Definições, p. 163)

Para Espinosa, o indivíduo mergulhado em afetos-paixões de tristeza, que orientam seu pensamento, apenas reage às afecções que o impressionam, pois tem sua potência de agir constrangida por aquilo que o impacta, ou seja, tem uma experiência passiva e dependente em relação a esses afetos. Desse modo, encontra dificuldades não somente em lidar com maus encontros com o mundo, mas em ser motivo de seus próprios afetos, em transformá-los em ação. O indivíduo, portanto, padece.

\footnotetext{
Chamo de servidão a impotência humana para regular e refrear os afetos. Pois o homem submetido aos afetos não está sob seu próprio comando, mas sob o do acaso, a cujo poder está a tal ponto sujeitado que é, muitas vezes, forçado, ainda que perceba o que é melhor para si, a fazer, entretanto, o pior. (SPINOZA, 2013, Ética, IV Parte, Prefácio, p. 263)
}

A servidão humana é o desconhecimento da forma pela qual somos afetados, em que o indivíduo entende as afecções sofridas apenas pela variação de potência que experimentou, atribuindo o afeto ao agente da afecção. Por isso, tido como conhecimento inadequado.

É, no entanto, por meio de afetos adequados que o indivíduo se torna virtuoso e capacitado a produzir a si mesmo. Afetos adequados são produzidos pelo entendimento num estado de ganho de potência, de desejo e alegria. A liberdade do indivíduo estaria vinculada exatamente a sua capacidade em lidar com afetos que favoreçam sua compreensão sobre o mundo e aumentem sua potência de pensar e agir. É adequado, portanto, o afeto que não nos torna refém do efeito que nos causa.

Da mesma forma que (segundo Espinosa) podemos alcançar conhecimento adequado por meio dos afetos, encontramos nos primeiros textos de Marx o entendimento de que é do mundo material que surge a emancipação do homem, num processo de embate ao determinismo nele contido. Afinal, se é da concretude da vida que os indivíduos transformam a realidade, é dela mesma que surge a saída. 
A maneira como os homens produzem seus meios de existência depende, antes de mais nada, da natureza dos meios de existência já encontrados e que eles precisam reproduzir. Não se deve considerar esse modo de produção sob esse único ponto de vista, ou seja, enquanto reprodução da existência física dos indivíduos. Ao contrário, ele representa, já, um modo determinado da atividade desses indivíduos, uma maneira determinada de manifestar sua vida, um modo de vida determinado. A maneira como os indivíduos manifestam sua vida reflete exatamente o que eles são. O que eles são coincide, pois, com sua produção, isto é, tanto com o que eles produzem quanto com a maneira como produzem. O que os indivíduos são depende, portanto, das condições materiais da sua produção. (MARX; ENGELS, 2002, p. 11)

[...] são os homens que, desenvolvendo sua produção material e suas relações materiais, transformam, com a realidade que lhe lhes é própria, seu pensamento e também os produtos de seu pensamento. (MARX; ENGELS, 2002, p. 19-20)

Apresentar a água é a tentativa central desta reflexão. A metáfora dos peixes nos mostra que o mais óbvio é o mais difícil de ser visto: "O ponto central da história dos peixes é que a realidade mais óbvia, ubíqua e importante é frequentemente a mais difícil de ver e discutir"3 (WALLACE, 2005, p. 1, tradução nossa). Nosso principal e constante esforço estaria em se posicionar frente a essa racionalidade social, que produz afetos passivos, utilizando-se de afetos adequados. Conforme Espinosa, afeto só se combate com afeto, mas, para tanto, temos primeiramente que nos abrir às experiências com o outro e com o mundo que favoreçam nossa potência, para poder ser afetado pela água, e dessa forma percebê-la, pois para escapar do movimento da maré, é mister saber que ela existe. O estado de consciência e empatia referido por Wallace se torna aqui conhecimento afetivo.

A frase inaugural da filosofia, "Tudo é água", de Tales de Mileto, só ganha correspondência com os dias de hoje se desprendida de seu sentido metafísico, e somente quando encontra seminal correspondência com a concretude da vida por uma afetividade mobilizadora.

\section{Bibliografia}

DARDOT, Pierre; LAVAL, Christian. A nova razão do mundo: ensaio sobre a sociedade neoliberal. São Paulo: Editora Boitempo, 2016.

FERREIRA, Amauri. Introdução à filosofia de Spinoza. São Paulo: Quebra Nozes, 2009.

MARX, Karl; ENGELS, Friedrich. A ideologia alemã. São Paulo: Martins Fontes, 2002.

SENNETT, Richard. A corrosão do caráter: consequências pessoais do trabalho no novo capitalismo. Rio de Janeiro: Record, 2015.

\footnotetext{
${ }^{3}$ The immediate point of the fish story is that the most obvious, ubiquitous, important realities are often the ones that are the hardest to see and talk about
} 
SPINOZA, Benedictus de. Ética. Belo Horizonte: Autêntica, 2013.

WALLACE, David Foster. This is Water: Some thoughts, delivered on a significant occasion, about living a compassionate life. Estados Unidos: Little Brown and Company, 2009.

\section{Internet}

LAVAL, Christian. Christian Laval: a racionalidade neoliberal [dublado]. 12 de novembro de 2018. (1h36min29s). Disponível <https://www.youtube.com/watch?v=bumpBiaXw84>. Acesso em: 05 março de 2019.

WALlACE, David F. Transcription of the 2005 Kenyon Commencement Address - May

21, 2005. Disponível: <https://web.ics.purdue.edu/ drkelly/DFWKenyonAddress2005.pdf>. Acesso em: 03 março de 2019. 